\title{
A Critical Overview of the Biological Effects of Mitomycin C Application on the Cornea Following Refractive Surgery
}

\author{
Esther Arranz-Marquez (D) - Andreas Katsanos (D) - Vassilios P. Kozobolis (D) · \\ Anastasios G. P. Konstas (D) - Miguel A. Teus
}

Received: January 17, 2019/ Published online: March 11, 2019

(c) The Author(s) 2019

\begin{abstract}
During the last 2 decades, modifying the shape of the cornea by means of laser photoablation has emerged as a successful and popular treatment option for refractive errors. Corneal surface ablation techniques such as photorefractive keratectomy (PRK) and laser-assisted
\end{abstract}

Enhanced Digital Features To view enhanced digital features for this article go to https://doi.org/10.6084/ m9.figshare.7689020.

E. Arranz-Marquez

Department of Ophthalmology, Rey Juan Carlos

University Hospital, Móstoles, Madrid, Spain

E. Arranz-Marquez · M. A. Teus

Clínica Novovisión, Madrid, Spain

A. Katsanos ( $\square)$

Department of Ophthalmology, University of

Ioannina, Ioannina, Greece

e-mail: katsanos@uoi.gr

V. P. Kozobolis

Department of Ophthalmology, Democritus

University of Thrace, Alexandroupolis, Greece

A. G. P. Konstas

1st and 3rd University Departments of

Ophthalmology, Aristotle University of

Thessaloniki, Thessaloniki, Greece

M. A. Teus

Department of Ophthalmology, Hospital

Universitario "Principe de Asturias", University of

Alcalá, Alcalá de Henares, Madrid, Spain subepithelial keratomileusis (LASEK) offer good refractive results while having a minimal impact on corneal biomechanical stability. Past limitations of these techniques included the long-term regression of refractive outcome and a vigorous healing response that reduced corneal clarity in some patients (giving rise to what is clinically described as "haze"). Mitomycin C (MMC) was introduced as a healing modulator and applied on the corneal surface after refractive surgery to address these drawbacks. This article critically reviews the available evidence on the biological effects, safety, and clinical benefits of the off-label use of MMC in corneal refractive surgery.

Keywords: Antimitotic; Haze; LASEK; Mitomycin C; MMC; Ophthalmology; PRK; Refractive surgery; Surface ablation

\section{INTRODUCTION}

Refractive errors, or ametropias, represent the most common visual problems affecting millions worldwide [1-3]. As refractive procedures have become safer, more refined and more affordable over time, their number has dramatically increased. Indeed, it has been argued that refractive surgery may represent the most cost-effective option for refractive correction [4]. 
Modern refractive surgery entails different techniques of ametropia correction. Corneal refractive procedures alter the refractive power of the eye by modifying the shape of the cornea, typically by means of an excimer laser [5]. In doing so, excimer lasers ablate thin segments of the cornea without inducing thermal effects and eventually alter its shape [5]. Excimer laser refractive surgery includes two main procedures: laser-assisted in situ keratomileusis (LASIK) in which the excimer laser is applied after a stromal corneal flap is fashioned and lifted [6], and surface ablation techniques in which the stromal ablation is directly performed after the corneal epithelium is removed or lifted [7]. Photorefractive keratectomy (PRK), a surface ablation technique, was the first excimer laser refractive procedure ever performed [7]. Soon after PRK became popular, laser-assisted subepithelial keratomileusis (LASEK), or advanced surface ablation (ASA), was introduced [8]. In LASEK, an epithelial flap is loosened off the stroma with the help of diluted alcohol and then retracted; next, the corneal stroma is ablated and the epithelial flap is put back in its original place [8]. LASEK has been found to offer some advantages over PRK [8].

Compared to LASIK, surface ablation procedures offer certain advantages: in addition to avoiding flap-related complications, surface ablations preserve more residual stromal tissue. Consequently, surface ablations are the techniques of choice in thin corneas or corneas with suspicious topographies [9]. The existing evidence suggests that refractive results with PRK, LASIK, or LASEK for the correction of low to moderate myopia are comparable [10-12].

A key concern with surface ablation procedures remains the development of postoperative corneal haze, i.e., decreased subepithelial corneal transparency related to aberrant epithelial and stromal wound healing processes $[13,14]$. It is well documented that in all patients soon after PRK or LASEK is performed, a corneal epithelial response is triggered [14-16]. This response initially consists of an increase in epithelial cell surface area in an effort to cover the surgically induced epithelial defect. This is then followed by epithelial cell proliferation, migration, hemidesmosome formation [16]. In parallel with the epithelial wound healing process, a cascade of stromal events is initiated by the cytokines released by the epithelial insult. This biological cascade involves keratocyte apoptosis followed by proliferation, migration, and fibroblast differentiation along with remodeling of the components of the extracellular matrix (ECM) [17]. After inducing wound contraction, those myofibroblasts normally disappear [18]. Surgery-induced damage to the basement membrane elicits this subepithelial fibrotic response, which is characterized by the production of disorganized stromal ECM by highly reflective activated keratocytes [19]. These tissue changes increase corneal light scattering, thus giving rise to biomicroscopically observable corneal haze [20]. Importantly, although some minor reduction of corneal transparency can be observed in most patients after surface ablation procedures, clinically significant corneal haze is rather uncommon as it has been reported in $2-4 \%$ of eyes after refractive surface ablation $[21,22]$. In the past, persisting, visually debilitating corneal haze was encountered in approximately $5 \%$ of cases after PRK procedures with the earlier generation lasers [23]. Factors known to increase the likelihood or severity of corneal haze include magnitude of corrections, delay of re-epithelization, irregularity of stromal surface, removal of epithelial basement membrane, injury to Bowman's layer, and excessive exposure to ultraviolet (UV-B) radiation $[21,22,24]$. Although more evidence is still required to characterize differences in the degree of haze induced by LASEK versus PRK, it seems that there are no clinically important differences between these two procedures in terms or postoperative risk of haze development [10].

Postoperative corneal haze usually manifests between the first and sixth month following the procedure and usually decreases gradually thereafter [13]. Two types with different temporal characteristics and prognosis can be distinguished: "early" corneal haze that usually begins within 1 week and 3 months postoperatively and regresses thereafter, and "late" corneal haze that tends to appear between 4 and 12 months postoperatively [25]. Late haze is 
typically more pronounced and more likely to reduce vision than early haze [25]. In the most severe cases, the presence of haze is associated with contrast sensitivity reduction, glare, refractive instability, irregular astigmatism, and decreased best corrected visual acuity [20].

The current review is based on previously conducted studies and does not contain any studies with human participants or animals performed by any of the authors.

\section{APPROACHES TO CONTROL HAZE}

Several treatment strategies have been proposed as a means of reducing the severity and incidence of early- or late-onset corneal haze after surface ablations. Alcohol-assisted epithelial removal [26] has been found to be marginally more effective than mechanical scraping in reducing subjective corneal haze in the early postoperative period, whereas the use of protective eyewear that blocks ultraviolet radiation [24] and the systemic administration of ascorbate [27] have been proposed as measures that might limit late-onset corneal haze. In view of the limited success with these approaches, most efforts have focused on the pharmacological modulation of wound healing, which constitutes the underlying pathophysiological process of corneal haze [20].

To limit aberrant healing-related processes such as excessive corneal infiltration by inflammatory cells, keratocyte activation, and myofibroblast differentiation, topical steroids (e.g., prednisolone acetate or fluorometholone) have been found effective in preventing or clearing corneal haze while instilled, but this improvement may be reduced after the discontinuation of steroids [28]. Cyclosporine A 0.05\% [28] and diclofenac [29] seem to have no meaningful effect on haze prevention after refractive surgery. A number of alternative approaches that aim at limiting myofibroblast differentiation have yet to produce clinically relevant results. These include plasma rich in growth factors (PRGF) [30], epigenetic modulation of transforming growth factor $\beta 1$ (TGF $\beta 1$ ) with inhibitors of histone acetyltransferase and histone deacetylase (trichostatin A [31], suberoylanilide hydroxamic acid, or vorinostat [32]), and gene therapy [33, 34].

Importantly, the introduction of mitomycin C (MMC) in refractive surgery in 1991 [35] has significantly improved clinical outcomes to the extent that its widespread clinical adoption as a prophylactic agent against postoperative corneal haze has led to the revival of interest in surface ablations in the last decade [36].

\section{INTRODUCTION TO MITOMYCIN C}

Mitomycin C is an antibiotic derived from Streptomyces species that was first described in 1956 [37]. The compound exhibits an alkylating action that inhibits cell mitosis by blocking DNA synthesis and has been widely used as a chemotherapeutic agent for non-small cell lung tumors and neoplasias of the bladder, prostate, and other organs [38].

As cells with a higher mitotic rate are more sensitive to its action, MMC began to be used in ophthalmic surgeries because of its action as a wound-healing modulator. The first report on the utilization of MMC in ophthalmic surgery was in 1963 as an adjunct to pterygium excision [39]. However, its usefulness in ophthalmic procedures became increasingly recognized at the early 1990s with the advent of MMC-augmented trabeculectomy [40]. At approximately the same time, an experimental study with rabbit eyes treated with MMC documented significant reduction of corneal haze after PRK [40]. Next, Carones and co-workers [41] produced convincing evidence for the benefits of the prophylactic use of MMC for the prevention of haze in human eyes undergoing PRK.

\section{CHEMISTRY}

Mitomycin C belongs to a class of antitumor antibiotics, the mitomycins. The compound is a methylazirinopyrroloindoledione $\left(\mathrm{C}_{15} \mathrm{H}_{18} \mathrm{~N}_{4} \mathrm{O}_{5}\right)$ (Fig. 1) with a molecular weight of $334 \mathrm{Da}$ that is soluble in water and other organic solvents. It is isolated from the bacterium Streptomyces caespitosus and other 
<smiles>CO[C@]12[C@H](COC(N)=O)C3=C(C(=O)C(C)=C(N)C3=O)N1C[C@H]1N[C@H]12</smiles>

Fig. 1 Chemical structure of mitomycin $\mathrm{C}$ $\left(\mathrm{C}_{15} \mathrm{H}_{18} \mathrm{~N}_{4} \mathrm{O}_{5}\right)$

Streptomyces bacterial species, and is commercially available as a powder made up of blueviolet crystals, that remains stable for at least 4 years at room temperature [42]. In its oxidized form MMC is inactive, so it requires chemical or enzymatic bioreductive activation (e.g., by $\mathrm{NADPH}$ cytochrome P450 reductase, NADPH cytochrome $\mathrm{C}$ reductase, DT-diaphorase, xanthine oxidase, or transhydrogenases) to either its semiquinone or hydroquinone form, in order to acquire its alkylating properties [42].

\section{PHARMACODYNAMICS}

The bioreductive (active) form of MMC binds DNA by bifunctional alkylation, preferentially at the guanine N2 position, leading to interstrand DNA cross-links [42, 43]. The cross-linking between the two strands prevents unwinding of DNA and therefore arrests DNA synthesis and cell mitosis [37, 43], preferentially in the late $\mathrm{G} 1$ and $\mathrm{S}$ phases of the cell cycle. MMC is also capable of inhibiting both RNA and protein synthesis, mostly in hypoxic conditions $[42,43]$.

In addition to its antimitotic effect, in vitro and in vivo studies have conclusively shown that MMC can inhibit the activation of human keratocytes and exhibit non-specific cell toxicity $[44,45]$. Both corneal epithelial injury and MMC have been linked to keratocyte loss observed in corneal stroma after ASA [46]. Cell loss by MMC is thought to be mainly due to apoptosis related to the mitochondrial pathway that is mediated by the caspase pathway [47]. However, it is not known as yet if MMC- induced apoptosis occurs only in rapidly proliferating keratocytes or if it can impact inactivated cells as well. This question is clinically relevant because MMC-induced apoptosis of inactive keratocytes could be responsible for long-term adverse effects such as corneal thinning [46]. Cellular death caused by MMC could also be related to other forms of cytotoxicity such as necrosis, since the compound upregulates cytokines and protein kinases [48], promotes T lymphocyte-mediated cell lysis [49], increases the levels of reactive oxygen species [50] and tumor necrosis factor [51], and reduces intracellular glutathione levels [52]. However, these adverse effects are generally encountered at higher MMC concentrations [45].

It has been shown that MMC has a time- and dose-dependent antiproliferative and cytotoxic effect on human keratocytes, but although both effects run in parallel to each other, they do not seem to occur simultaneously [36, 45]. It has been calculated in vitro that the $\mathrm{ID}_{50}$ (inhibitory dose $50 \%$ ) of MMC for human keratocytes is quite different from the $\mathrm{LD}_{50}$ (lethal dose 50\%) [45]. In other words, the dose needed to inhibit cell proliferation is considerably smaller than that required for cell death $\left(\mathrm{ID}_{50}=0.0048 \mathrm{mg} / \mathrm{mL}\right.$ vs $\left.\mathrm{LD}_{50}=0.28 \mathrm{mg} / \mathrm{mL}\right)$. It should be emphasized here that the long-term effects of this agent on ocular tissues remain to be fully elucidated in the future, as it is currently unclear whether MMC-affected cells are able to repair the MMC-induced damage, or whether these effects are permanent $[53,54]$.

\section{PHARMACOKINETICS AND METABOLISM}

Experimental in vivo studies in rabbits have demonstrated that the maximal corneal concentration of MMC after standard topical application (i.e., application of a sponge soaked in $0.02 \% \mathrm{MMC}$ for $2 \mathrm{~min}$ ) reaches its peak of $3.728 \pm 2.547 \mu \mathrm{g} / \mathrm{g}$ after $30 \mathrm{~min}$ and decreases to $0.756 \pm 0.437 \mu \mathrm{g} / \mathrm{g}$ at $1 \mathrm{~h}$ [55]. It has also been reported that MMC applied on the cornea can be detected in the aqueous humor [55-57] even with low concentrations (e.g., 0.005\%) and short application times (15s), reaching 
peak concentration in the anterior chamber of around $0.380 \mu \mathrm{g} / \mathrm{mL} 1 \mathrm{~h}$ after its administration [55]. Moreover, MMC can be detected in the cornea and aqueous humor for $3 \mathrm{~h}$ after corneal application [55]. It should be noted that when MMC is applied during refractive procedures, the permeation of the drug down to the deepest corneal layers and the anterior chamber is facilitated by the absence of an intact epithelium and the thinner residual corneal stroma [55]. The aqueous concentration of MMC after the drug is applied on the corneal surface significantly increases with increasing concentrations, duration of application, and amount of attempted refractive correction $[55,58]$. However, the number of apoptotic stromal keratocytes significantly correlates with MMC concentration, but not with application time [55]. It should be noted, however, that as with all surgical procedures, differences in technique might account for differences in outcomes. For example, one could speculate that the pharmacokinetics of MMC when applied on dry corneal stroma (i.e., immediately after the ablation) is different than the pharmacokinetics of the drug when applied on wet corneal stroma (e.g., following the flushing of the photo-ablated stromal bed with balanced salt solution).

It seems that MMC clearance from ocular tissues following topical application is quite rapid, a process possibly augmented by the thorough irrigation that is typically done in ASA [59]. Of note, the half-life of the drug is not affected [59]. This is the reason why some authors believe that a single, brief exposure to MMC during surface ablation is sufficient for the inhibition of keratocyte proliferation, but not sufficient to induce meaningful keratocyte loss $[36,60]$. Besides, reducing the exposure time without changing the concentration of MMC can reduce the subsequent penetration of the drug to the anterior chamber, and thus limit the potential toxicity to endothelial cells while still maintaining an appreciable effect on keratocyte apoptosis [55].

There has been evidence on the systemic absorption of MMC when large doses are used over wide areas of highly vascularized mucosas [61]. Although MMC has a short plasma half-life of approximately $20 \mathrm{~min}$ [62] mainly due to its rapid hepatic clearance, adverse effects such as bone marrow suppression, renal and hepatic toxicity have rarely occurred after chemotherapy with large doses of this drug for bladder and peritoneal carcinomas [61]. However, only two published studies to date have reported on the systemic absorption of MMC after topical ocular application; neither its application to the sclera in pterygium surgery [63] nor to the cornea in refractive procedures [64] resulted in measurable systemic absorption. Overall, pharmacokinetics, pharmacodynamics, and metabolism data show that MMC is unlikely to induce ocular or systemic toxicity when used topically for the prevention or treatment of corneal haze associated with surface ablation procedures.

\section{CLINICAL EFFICACY}

Topically applied MMC in surface refractive surgery is effective in preventing and treating subepithelial haze $[36,65]$. The clinical efficacy of MMC in controlling haze is supported by in vivo confocal microscopy studies $[36,66,67]$. It has been found that activated keratocytes and ECM are less conspicuous in MMC-treated corneas compared to untreated ones [66]. In addition, the application of MMC during surface refractive surgery is accompanied by a temporal redistribution of keratocyte density throughout the corneal stroma [67]. That is, an initial depletion of keratocytes at the anterior stromal layers is compensated by an increase of these cells in deeper layers; this pattern is followed over time by a tendency of the cell density to normalize across the cornea [67]. This observation may suggest that either deeper stromal keratocytes are less affected by MMC or that the population of these cells recovers faster from bone marrow-derived cells compared to keratocytes of the anterior cornea $[67,68]$.

Since the first report by Majmudar et al. who demonstrated the usefulness of MMC as a corneal healing modulator in the management of subepithelial scarring after radial keratotomy, or PRK [69], MMC has become the first-line treatment for established haze. Indeed, even today MMC is still used for the same indication in the dosage used by Majmudar and co-workers, i.e., 
at a concentration of $0.02 \%$ for 2 min over the treated stroma [69]. However, there is convincing evidence that this MMC regimen is far superior in preventing postoperative haze and in removing myofibroblasts when used prophylactically rather than therapeutically [70]. Consequently, nowadays the widespread prophylactic use of MMC with surface ablations has led to the significant reduction in the occurrence and severity of postoperative corneal haze $[36,65,66]$.

Currently, the prophylactic application of topical MMC in refractive surgery has been extended to LASEK [71] and it is particularly being used for patients at risk of developing postoperative corneal haze, or regression, such as cases of surface ablation performed over previous PRK, LASIK, buttonholed or incomplete LASIK flaps, radial keratotomy, or penetrating keratoplasty [72].

The corneal healing response differs among individuals but there may also exist particular cellular, metabolic, or environmental conditions that predispose to postoperative haze in certain corneas after primary surface ablation surgery $[73,74]$. To date, there is no established ablation depth above which the risk of haze is eliminated. Depending on ablation depth, protocols for the prophylactic use of MMC during primary myopic ASA have been suggested [72]. Depths of ablation beyond $50-75 \mu \mathrm{m}$ and corrections exceeding -4.0 or -6.0 diopters (D) are generally considered useful cutoffs $[9,72]$. On the other hand, there is practically no controlled evidence on the preoperative use of MMC in hyperopic surface ablations. However, it may be advisable to use MMC even with low hyperopic corrections because postoperative haze seems to be more common after hyperopic than myopic treatments [72].

Despite the available published evidence and cumulated clinical experience after many years of MMC administration for the prevention and treatment of corneal haze, one should remember that just like in glaucoma surgery, the use of this agent remains "off-label" for corneal refractive surgery. Obviously, this should be clearly communicated to patients.

The dosing of prophylactic MMC application continues to be a topic of debate in refractive surgery [36, 65, 72]. Larger doses and longer application times increase the risk of adverse effects when performing surface ablations. Although more evidence is needed to precisely document the efficacy of lower concentrations, nowadays MMC $0.02 \%$ applied with a soaked cellulose sponge intraoperatively over the central ablated corneal stroma for a period between $12 \mathrm{~s}$ and $1 \mathrm{~min}$, followed by thorough irrigation with balanced salt solution, seems to be the most effective and safe option for ASA treatments [36]. On the other hand, the efficacy of MMC as a haze-preventing agent may be influenced by factors other than concentration and exposure time, such as technique variations in epithelium removal, characteristics of the sponge, etc. Using corneal shields of fixed dimensions and properties has been suggested as a novel approach that could help standardize and improve the intraoperative delivery of MMC [75].

\section{SAFETY AND TOLERABILITY}

As the main therapeutic effect of MMC is the prevention of cell replication, it is reasonable to assume that adverse effects of this drug could target layers of the cornea composed of cells with higher mitotic rates, such as the epithelium and the stroma. At least in principle, permanent depletion of stromal keratocytes could lead to biomechanical corneal instability. This risk, however, is not supported by controlled evidence. Some experimental studies have documented a small decrease in the number of stromal keratocytes following MMC application over a short follow-up period [60, 70]. Although one study with longer follow-up did not observe increased loss of keratocytes in the anterior stroma [60], others have documented a delay in keratocyte repopulation in the anterior stroma, which may take 6-12 months to recover its original cell density $[66,67,76]$. However, it has been suggested that keratocytes arrested by MMC may still maintain their self-repairing capabilities as well as continue to contribute to crucial aspects of wound healing such as migration and stimulation of intact keratocytes located in deeper layers of the stroma [54, 66]. 
The fact that prophylactic MMC treatment in refractive procedures does not deplete the functional reserves of keratocytes is corroborated by reports on the development of late haze after uneventful surface ablation with prophylactic MMC [77], and the fact that ectasia has yet to be reported after MMC-augmented surface ablation.

As epithelial cells have a rapid turnover rate, one could expect that these cells would be particularly vulnerable to MMC. Using an in vitro human cornea model in which MMC 0.02\% was applied for 1 or $2 \mathrm{~min}$ during myopic PRK, Rajan et al. documented that 4 weeks after the procedure, compared to the control group, MMC-treated corneas had poorly differentiated and thinner epithelial cells that exhibited a slower migration speed with a consequent delay on wound closure [60]. In a large retrospective study, Kremer et al. [78] observed that $3.5 \%$ of myopes treated with PRK and MMC $(0.02 \%$ for 20 s) had a significant epithelial healing delay. In this study, however, the postoperative use of dexamethasone and diclofenac eye drops may have influenced epithelial regeneration [78]. Besides, a 6-month randomized trial showed that the prophylactic use of MMC $(0.02 \%$ for $15 \mathrm{~s})$ in patients undergoing PRK for mild myopia (spherical equivalent -0.75 to $-3.87 \mathrm{D}$ ) does not induce any appreciable changes in tear film index, total higher order aberrations, or haze compared to the placebotreated contralateral eyes [79]. Although most clinical studies with short duration of MMC application during ASA suggest the lack of significant epithelial toxicity [36], it seems prudent to be cautious with exposure time as well as avoid the contact of the drug with the intact epithelium surrounding the treatment area and the limbal zone.

Animal experiments have shown that MMCrelated endothelial toxicity can indeed occur $[80,81]$. In an experimental study, intact goat globes exposed to MMC in a manner similar to refractive surgery have revealed histopathological evidence of endothelial damage such as DNA cross-linking and apoptosis [80]. In a rabbit model, Chang et al. observed dose-dependent corneal edema after MMC use as a result of a decrease in endothelial cell population [81]. It should be noted, however, that there are important differences across species in endothelial physiology: contrary to human corneal endothelial cells, rabbit endothelial cells have a high mitotic rate [81]. In humans, in vitro direct application of $200 \mu \mathrm{g} / \mathrm{mL}$ of MMC on endothelial cells induces corneal edema whereas exposure to $20 \mu \mathrm{g} / \mathrm{mL}$ of MMC causes no apparent ultrastructural changes [82]. MMC topically applied to human corneas has been shown to penetrate across all corneal layers but the ultimate aqueous humor concentration after routine application in refractive surgery is far lower than the levels considered harmful $[55,57]$. Importantly, the majority of human clinical studies exploring the endothelial adverse effects of MMC after refractive surgery have reported no endothelial changes at all $[36,65]$, but three prospective studies detected endothelial cell changes after topical MMC application in ASA [83-85]. Of these studies, the two with the bigger sample size found either a minimal decrease in endothelial cell density $(0.47 \%)$ [84] or an increase in the standard deviation of cell size and coefficient of variation (but not in endothelial cell density or cell size) [85]. Besides the case report of visually debilitating corneal edema developing after therapeutic application of MMC for the treatment of post-ablation haze in a patient who underwent phototherapeutic keratectomy and used 14 drops of the drug $(0.02 \%)$ over a period of 6 days [86], no human studies have reported sight-threatening complications such as endothelial decompensation [65]. However, the precise long-term effects of MMC on the corneal endothelial physiology need to be further elucidated. The potential effects of MMC in the juxtacanalicular tissue and the endothelial cells of Schlemm's canal also warrant investigation.

In animals, contrary to what has been observed when MMC is applied trans-sclerally [87], there is no microscopic or functional change in the ciliary body when the drug is applied over the ablated corneal stroma [88]. Data for the potential effect of MMC in human ciliary bodies when the compound is used in ablated corneas are currently not available. The likelihood of systemic toxicity due to absorption in the bloodstream of MMC topically 
applied during ASA seems almost non-existent [64].

Corneal shields with fixed dimensions and properties may be useful in delivering a constant dose of MMC confined at the central part of the cornea [75]. Such shields, in addition to standardizing the dose of medication, would reduce the risk of adverse events due to exposure of limbal stem cells to the drug [75]. Besides MMC, novel investigational approaches on the modulation of wound healing are underway and may further improve the safety and efficacy of corneal refractive surgery [30, 32, 89].

\section{REGULATORY ISSUES}

As already mentioned, despite the wealth of supporting controlled evidence for the value of the adjunctive use of MMC in ophthalmic surgical procedures, its use is still considered "offlabel". Although the existing published literature has convincingly demonstrated the safety and efficacy of the compound when used as discussed in previous sections for ASA, clinicians should be aware of the possibility of medicolegal or reimbursement issues with its use. Therefore the importance of obtaining patient's consent for its use should be emphasized.

\section{CONCLUSION}

Undoubtedly the application of topical MMC significantly reduces the risk of haze after refractive surface ablation procedures. Nevertheless, the precise dosing and indications for prophylactic MMC application continue to be a topic of debate. Cumulative evidence suggests that with current surface ablation techniques $0.02 \%$ MMC should be an optimal concentration for treating moderate to high myopia (i.e., corrections beyond $-4.0 \mathrm{D}$ or depth of ablation more than $50 \mu \mathrm{m}$ ). More data are needed to analyze the value and clinical usefulness of weaker concentrations (e.g., $0.002 \%$ or $0.01 \%$ ) and the role of prophylactic MMC in retreatments. Today there is insufficient evidence for the optimal duration of MMC application, but current clinical practice is to apply the drug for $12-60 \mathrm{~s}$. It is worthwhile noting that there is a general tendency in most refractive centers to shorten the duration of MMC application.

Available evidence supports the concept that the intraoperative corneal application of $0.02 \%$ MMC in refractive surgery has not been linked to significant and clinically relevant corneal toxicity. However, more in-depth investigation is needed to better document the long-term impact of MMC on stromal cell populations and its effect on corneal biomechanical and refractive stability.

\section{ACKNOWLEDGEMENTS}

Funding. No funding or sponsorship was received for this review or publication of this article.

Authorship. All named authors meet the International Committee of Medical Journal Editors (ICMJE) criteria for authorship for this article, take responsibility for the integrity of the work as a whole, and have given their approval for this version to be published.

Disclosures. Esther Arranz-Marquez has received congress expenses from Allergan, Santen, Nicox, and Laboratoires Théa. Andreas Katsanos has received lecture fees and congress expenses from Novartis, Allergan, Santen, and Laboratoires Théa and is a member of the journal's Editorial Board. Anastasios G. P. Konstas has received research support from Allergan, Bayer Hellas, Pharmathen Hellas S.A., and Santen, honoraria from Allergan and Santen, and congress expenses covered by Bayer Hellas, Santen, and Vianex, and is a member of the journal's Editorial Board. Miguel A. Teus has received congress expenses from Johnson \& Johnson, Alcon, Novartis, and Laboratoires Théa, lecture fees from Johnson \& Johnson, Alcon, Allergan, and Novartis and is a consultant for Alcon, Allergan, Novartis, and Santen. Vassilios P. Kozobolis has nothing to disclose. 
Compliance with Ethics Guidelines. This article is based on previously conducted studies and does not contain any studies with human participants or animals performed by any of the authors.

Open Access. This article is distributed under the terms of the Creative Commons Attribution-NonCommercial 4.0 International License (http://creativecommons.org/licenses/ by-nc/4.0/), which permits any noncommercial use, distribution, and reproduction in any medium, provided you give appropriate credit to the original author(s) and the source, provide a link to the Creative Commons license, and indicate if changes were made.

\section{REFERENCES}

1. GBD 2015 Disease and Injury Incidence and Prevalence Collaborators. Global, regional, and national incidence, prevalence, and years lived with disability for 310 diseases and injuries, 1990-2015: a systematic analysis for the Global Burden of Disease Study 2015. Lancet. 2016;388:1545-602.

2. Hashemi H, Fotouhi A, Yekta A, et al. Global and regional estimates of prevalence of refractive errors: systematic review and meta-analysis. J Curr Ophthalmol. 2018;30:3-22.

3. Kandel H, Khadka J, Goggin M, Pesudovs K. Impact of refractive error on quality of life: a qualitative study. Clin Exp Ophthalmol. 2017;45:677-88.

4. Mohammadi S-F, Alinia C, Tavakkoli $\mathrm{M}$, et al. Refractive surgery: the most cost-saving technique in refractive errors correction. Int J Ophthalmol. 2018;11:1013-9.

5. Trokel SL, Srinivasan R, Braren B. Excimer laser surgery of the cornea. Am J Ophthalmol. 1983;96:710-5.

6. Pallikaris IG, Papatzanaki ME, Stathi EZ, et al. Laser in situ keratomileusis. Lasers Surg Med. 1990;10:463-8.

7. Munnerlyn CR, Koons SJ, Marshall J. Photorefractive keratectomy: a technique for laser refractive surgery. J Cataract Refract Surg. 1988;14:46-52.

8. Azar DT, Ang RT, Lee JB, et al. Laser subepithelial keratomileusis: electron microscopy and visual outcomes of flap photorefractive keratectomy. Curr Opin Ophthalmol. 2001;12:323-8.

9. Garcia-Gonzalez M, Drake Rodriguez-Casanova P, Rodriguez-Perez I, et al. Long-term follow-up of LASEK with mitomycin C performed to correct myopia in thin corneas. J Refract Surg. 2017;33:813-9.

10. Li S-M, Zhan S, Li S-Y, et al. Laser-assisted subepithelial keratectomy (LASEK) versus photorefractive keratectomy (PRK) for correction of myopia. Cochrane Database Syst Rev. 2016;2:CD009799.

11. Kuryan J, Cheema A, Chuck RS. Laser-assisted subepithelial keratectomy (LASEK) versus laser-assisted in situ keratomileusis (LASIK) for correcting myopia. Cochrane Database Syst Rev. 2017;2:CD011080.

12. Wen D, McAlinden C, Flitcroft I, et al. Postoperative efficacy, predictability, safety, and visual quality of laser corneal refractive surgery: a network metaanalysis. Am J Ophthalmol. 2017;178:65-78.

13. Erie JC. Corneal wound healing after photorefractive keratectomy: a 3-year confocal microscopy study. Trans Am Ophthalmol Soc. 2003;101:293-333.

14. Torricelli AAM, Santhanam A, Wu J, et al. The corneal fibrosis response to epithelial-stromal injury. Exp Eye Res. 2016;142:110-8.

15. Marino GK, Santhiago MR, Torricelli AAM, et al. Corneal molecular and cellular biology for the refractive surgeon: the critical role of the epithelial basement membrane. J Refract Surg. 2016;32:118-25.

16. Dua HS, Gomes JA, Singh A. Corneal epithelial wound healing. Br J Ophthalmol. 1994;78:401-8.

17. Taliana L, Evans MD, Dimitrijevich SD, Steele JG. Vitronectin or fibronectin is required for corneal fibroblast-seeded collagen gel contraction. Invest Ophthalmol Vis Sci. 2000;41:103-9.

18. Wilson SE, Mohan RR, Hong JW, et al. The wound healing response after laser in situ keratomileusis and photorefractive keratectomy: elusive control of biological variability and effect on custom laser vision correction. Arch Ophthalmol. 2001;119:889-96.

19. Corbett MC, Prydal JI, Verma S, et al. An in vivo investigation of the structures responsible for corneal haze after photorefractive keratectomy and their effect on visual function. Ophthalmology. 1996;103:1366-80. 
20. Moller-Pedersen T, Cavanagh HD, Petroll WM, Jester JV. Stromal wound healing explains refractive instability and haze development after photorefractive keratectomy: a 1-year confocal microscopic study. Ophthalmology. 2000;107:1235-45.

21. Netto MV, Mohan RR, Sinha S, et al. Stromal haze, myofibroblasts, and surface irregularity after PRK. Exp Eye Res. 2006;82:788-97.

22. Tomás-Juan J, Murueta-Goyena Larrañaga A, Hanneken L. Corneal regeneration after photorefractive keratectomy: a review. J Optom. 2015;8:149-69.

23. Seiler T, Holschbach A, Derse M, et al. Complications of myopic photorefractive keratectomy with the excimer laser. Ophthalmology. $1994 ; 101: 153-60$.

24. Stojanovic A, Nitter TA. Correlation between ultraviolet radiation level and the incidence of lateonset corneal haze after photorefractive keratectomy. J Cataract Refract Surg. 2001;27:404-10.

25. Kaiserman I, Sadi N, Mimouni M, et al. Corneal breakthrough haze after photorefractive keratectomy with mitomycin C: incidence and risk factors. Cornea. 2017;36:961-6.

26. Abad JC, An B, Power WJ, et al. A prospective evaluation of alcohol-assisted versus mechanical epithelial removal before photorefractive keratectomy. Ophthalmology. 1997;104:1566-74 (discussion 1574-1575).

27. Stojanovic A, Ringvold A, Nitter T. Ascorbate prophylaxis for corneal haze after photorefractive keratectomy. J Refract Surg. 2003;19:338-43.

28. Nien CJ, Flynn KJ, Chang M, et al. Reducing peak corneal haze after photorefractive keratectomy in rabbits: prednisolone acetate $1.00 \%$ versus cyclosporine A $0.05 \%$. J Cataract Refract Surg. 2011;37:937-44.

29. Nassaralla BA, Szerenyi K, Wang XW, et al. Effect of diclofenac on corneal haze after photorefractive keratectomy in rabbits. Ophthalmology. 1995;102:469-74.

30. Anitua E, de la Fuente M, Muruzabal F, et al. Plasma rich in growth factors (PRGF) eye drops stimulates scarless regeneration compared to autologous serum in the ocular surface stromal fibroblasts. Exp Eye Res. 2015;135:118-26.

31. Sharma A, Mehan MM, Sinha S, et al. Trichostatin a inhibits corneal haze in vitro and in vivo. Invest Ophthalmol Vis Sci. 2009;50:2695-701.

32. Anumanthan G, Sharma A, Waggoner M, et al. Efficacy and safety comparison between suberoylanilide hydroxamic acid and mitomycin C in reducing the risk of corneal haze after PRK treatment in vivo. J Refract Surg. 2017;33:834-9.

33. Mohan RR, Gupta R, Mehan MK, et al. Decorin transfection suppresses profibrogenic genes and myofibroblast formation in human corneal fibroblasts. Exp Eye Res. 2010;91:238-45.

34. Gupta S, Rodier JT, et al. Targeted AAV5-Smad7 gene therapy inhibits corneal scarring in vivo. PLoS One. 2017;12:e0172928.

35. Talamo JH, Gollamudi S, Green WR, et al. Modulation of corneal wound healing after excimer laser keratomileusis using topical mitomycin $\mathrm{C}$ and steroids. Arch Ophthalmol. 1991;109:1141-6.

36. Teus MA, de Benito-Llopis L, Alió JL. Mitomycin C in corneal refractive surgery. Surv Ophthalmol. 2009;54:487-502.

37. Hata T, Hoshi T, Kanamori K, et al. Mitomycin, a new antibiotic from Streptomyces. I. J Antibiot. 1956;9:141-6.

38. Verweij J, Pinedo HM. Mitomycin C: mechanism of action, usefulness and limitations. Anticancer Drugs. 1990;1:5-13.

39. Kunimoto N, Mori S. Studies on pterygium. Part IV. A treatment of the pterygium by mitomycin-C instillation. Nippon Ganka Gakkai Zasshi. 1963;67:601-7.

40. Palmer SS. Mitomycin as adjunct chemotherapy with trabeculectomy. Ophthalmology. 1991;98:317-21.

41. Carones F, Vigo L, Scandola E, Vacchini L. Evaluation of the prophylactic use of mitomycin-C to inhibit haze formation after photorefractive keratectomy. J Cataract Refract Surg. 2002;28:2088-95.

42. US National Library of Medicine, Toxicology Data Network. TOXNET. https://toxnet.nlm.nih.gov/cgibin/sis/search2/f?./temp/ qkQSMn:1. Accessed 28 Dec 2018.

43. Mladenov E, Tsaneva I, Anachkova B. Activation of the $\mathrm{S}$ phase DNA damage checkpoint by mitomycin C. J Cell Physiol. 2007;211:468-76.

44. Lown J. The molecular mechanism of action of the mitomycins. In: Carter S, Crooke S, editors. Mitomycin C, current status and new developments. New York: Academic; 1979. p. 5-26.

45. Sadeghi HM, Seitz B, Hayashi S, et al. In vitro effects of mitomycin-C on human keratocytes. J Refract Surg. 1998;14:534-40. 
46. Dupps WJ, Wilson SE. Biomechanics and wound healing in the cornea. Exp Eye Res. 2006;83:709-20.

47. Kim T, Tchah H, Lee S, et al. Apoptosis in keratocytes caused by mitomycin C. Invest Ophthalmol Vis Sci. 2003;44:1912-7.

48. Chou S-F, Chang S-W, Chuang J-L. Mitomycin C upregulates IL-8 and MCP-1 chemokine expression via mitogen-activated protein kinases in corneal fibroblasts. Invest Ophthalmol Vis Sci. 2007;48:2009-16.

49. Crowston JG, Chang LH, Daniels JT, et al. T lymphocyte mediated lysis of mitomycin $\mathrm{C}$ treated Tenon's capsule fibroblasts. Br J Ophthalmol. 2004;88:399-405.

50. Pritsos CA, Sartorelli AC. Generation of reactive oxygen radicals through bioactivation of mitomycin antibiotics. Cancer Res. 1986;46:3528-32.

51. Pogrebniak HW, Matthews W, Pass HI. Chemotherapy amplifies production of tumor necrosis factor. Surgery. 1991;110:231-7.

52. Goeptar AR, Groot EJ, Scheerens H, et al. Cytotoxicity of mitomycin $\mathrm{C}$ and adriamycin in freshly isolated rat hepatocytes: the role of cytochrome P450. Cancer Res. 1994;54:2411-8.

53. Lee Y-J, Park S-J, Ciccone SLM, et al. An in vivo analysis of MMC-induced DNA damage and its repair. Carcinogenesis. 2006;27:446-53.

54. Occleston NL, Daniels JT, Tarnuzzer RW, et al. Single exposures to antiproliferatives: long-term effects on ocular fibroblast wound-healing behavior. Invest Ophthalmol Vis Sci. 1997;38:1998-2007.

55. Song J-S, Kim J-H, Yang M, et al. Mitomycin-C concentration in cornea and aqueous humor and apoptosis in the stroma after topical mitomycin- $\mathrm{C}$ application: effects of mitomycin-C application time and concentration. Cornea. 2007;26:461-7.

56. Chang S-W. Corneal keratocyte apoptosis following topical intraoperative mitomycin C in rabbits. J Refract Surg. 2005;21:446-53.

57. Torres RM, Merayo-Lloves J, Daya SM, et al. Presence of mitomycin- $C$ in the anterior chamber after photorefractive keratectomy. J Cataract Refract Surg. 2006;32:67-71.

58. Kymionis GD, Diakonis VF, Panagopoulou SI, et al. Mitomycin $\mathrm{C}$ aqueous humor concentration after photorefractive keratectomy: an experimental study. Eur J Ophthalmol. 2009;19:738-42.

59. Kawase K, Matsushita H, Yamamoto T, Kitazawa Y. Mitomycin concentration in rabbit and human ocular tissues after topical administration. Ophthalmology. 1992;99:203-7.

60. Rajan MS, O'Brart DPS, Patmore A, Marshall J. Cellular effects of mitomycin-C on human corneas after photorefractive keratectomy. J Cataract Refract Surg. 2006;32:1741-7.

61. Kuzuya T, Yamauchi M, Ito A, et al. Pharmacokinetic characteristics of 5-fluorouracil and mitomycin C in intraperitoneal chemotherapy. J Pharm Pharmacol. 1994;46:685-9.

62. Kemp EG, Harnett AN, Chatterjee S. Preoperative topical and intraoperative local mitomycin $\mathrm{C}$ adjuvant therapy in the management of ocular surface neoplasias. Br J Ophthalmol. 2002;86:31-4.

63. Yulish M, Khatib A, Pikkel J. Systemic absorption of Mitomycin-C when used in pterygium surgery. Cornea. 2018;37:746-7.

64. Crawford C, Ainbinder DJ, Davis R, et al. Systemic absorption of mitomycin-C when used in refractive surgery. J Cataract Refract Surg. 2013;39:193-6.

65. Majmudar PA, Schallhorn SC, Cason JB, et al. Mitomycin-C in corneal surface excimer laser ablation techniques: a report by the American Academy of Ophthalmology. 2015;122:1085-95.

Ophthalmology.

66. Gambato C, Ghirlando A, Moretto E, et al. Mitomycin C modulation of corneal wound healing after photorefractive keratectomy in highly myopic eyes. Ophthalmology. 2005;112:208-18 (discussion 219).

67. de Benito-Llopis L, Cañadas P, Drake P, et al. Keratocyte density 3 months, 15 months, and 3 years after corneal surface ablation with mitomycin C. Am J Ophthalmol. 2012;153(17-23):e1.

68. Barbosa FL, Chaurasia SS, Cutler A, et al. Corneal myofibroblast generation from bone marrowderived cells. Exp Eye Res. 2010;91:92-6.

69. Majmudar PA, Forstot SL, Nirankari VS, et al. Topical mitomycin-C for subepithelial fibrosis after corneal surgery. Ophthalmology. 2000;107:89-94.

70. Netto MV, Mohan RR, Sinha S, et al. Effect of prophylactic and therapeutic mitomycin $\mathrm{C}$ on corneal apoptosis, cellular proliferation, haze, and longterm keratocyte density in rabbits. J Refract Surg. 2006;22:562-74.

71. Camellin M. Laser epithelial keratomileusis with mitomycin C: indications and limits. J Refract Surg. 2004;20:S693-8. 
72. Lacayo GO, Majmudar PA. How and when to use mitomycin-C in refractive surgery. Curr Opin Ophthalmol. 2005;16:256-9.

73. Maldonado MJ. Intraoperative MMC after excimer laser surgery for myopia. Ophthalmology. 2002;109:826 (author reply 826-828).

74. Daniels JT, Occleston NL, Crowston JG, Khaw PT. Effects of antimetabolite induced cellular growth arrest on fibroblast-fibroblast interactions. Exp Eye Res. 1999;69:117-27.

75. Khoury JM, Farah T, El-Haibi CP, Noureddin BN. Corneal light shield as a delivery system for standardized application of mitomycin C in excimer surface ablation. J Refract Surg. 2007;23:716-9.

76. Midena E, Gambato C, Miotto S, et al. Long-term effects on corneal keratocytes of mitomycin $\mathrm{C}$ during photorefractive keratectomy: a randomized contralateral eye confocal microscopy study. J Refract Surg. 2007;23:S1011-4.

77. Qazi MA, Johnson TW, Pepose JS. Development of late-onset subepithelial corneal haze after laser-assisted subepithelial keratectomy with prophylactic intraoperative mitomycin-C. Case report and literature review. J Cataract Refract Surg. 2006;32:1573-8.

78. Kremer I, Ehrenberg M, Levinger S. Delayed epithelial healing following photorefractive keratectomy with mitomycin C treatment. Acta Ophthalmol. 2012;90:271-6.

79. Mohammadi SF, Ashrafi E, Norouzi N, et al. Effects of mitomycin-C on tear film, corneal biomechanics, and surface irregularity in mild to moderate myopic surface ablation: preliminary results. J Cataract Refract Surg. 2014;40:937-42.

80. Roh DS, Cook AL, Rhee SS, et al. DNA cross-linking, double-strand breaks, and apoptosis in corneal endothelial cells after a single exposure to mitomycin C. Invest Ophthalmol Vis Sci. 2008;49:4837-43.
81. Chang S-W. Early corneal edema following topical application of mitomycin-C. J Cataract Refract Surg. 2004;30:1742-50.

82. McDermott ML, Wang J, Shin DH. Mitomycin and the human corneal endothelium. Arch Ophthalmol. 1994;112:533-7.

83. Morales AJ, Zadok D, Mora-Retana R, et al. Intraoperative mitomycin and corneal endothelium after photorefractive keratectomy. Am J Ophthalmol. 2006;142:400-4.

84. Nassiri N, Farahangiz S, Rahnavardi M, et al. Corneal endothelial cell injury induced by mitomycin$\mathrm{C}$ in photorefractive keratectomy: nonrandomized controlled trial. J Cataract Refract Surg. 2008;34:902-8.

85. Gharaee H, Zarei-Ghanavati S, Alizadeh R, Abrishami M. Endothelial cell changes after photorefractive keratectomy with graded usage of mitomycin C. Int Ophthalmol. 2018;38:1211-7.

86. Pfister RR. Permanent corneal edema resulting from the treatment of PTK corneal haze with mitomycin: a case report. Cornea. 2004;23:744-7.

87. Schraermeyer U, Diestelhorst M, Bieker A, et al. Morphologic proof of the toxicity of mitomycin C on the ciliary body in relation to different application methods. Graefes Arch Clin Exp Ophthalmol. 1999;237:593-600.

88. Kymionis GD, Diakonis VF, Charisis S, et al. Effects of topical mitomycin C on the ciliary body and intraocular pressure after PRK: an experimental study. J Refract Surg. 2008;24:633-8.

89. Kim HK, Choi J-Y, Park SM, et al. Tyrosine kinase inhibitor, vatalanib, inhibits proliferation and migration of human pterygial fibroblasts. Cornea. 2017;36:1116-23. 